\title{
Genetic Diversity among Tomato (Solanum lycopersicum L.) Genotypes
}

\author{
B. Srinivasulu ${ }^{1 *}$, Pradeep Kumar Singh ${ }^{1}$, G. Harika² and C. Sai Prashanth \\ ${ }^{1}$ Division of Vegetable Science, Sher-e-Kashmir University of Agricultural Sciences and \\ Technology, Shalimar, Srinagar-19000, India \\ ${ }^{2}$ College of Horticulture, Venkataramannagudem, West Godavari, A.P, India \\ *Corresponding author
}

\begin{abstract}
Keywords
Genetic Diversity,

Cluster analysis,

Mahalonobis D ${ }^{2}$,

Solanum

lycopersicum $\mathrm{L}$.

Article Info

Accepted:

20 January 2020

Available Online:

10 February 2020 the genetic diversity among tomato genotypes for fruit yield and its attributing characters. Mahalanobis distance $\left(\mathrm{D}^{2}\right)$ was used to estimate the genetic distance between pair of clusters. Estimates of cluster analysis revealed that the twenty seven genotypes were grouped into eight distinct clusters. Genetic distance between any pair of clusters showed highly significant difference. Cluster I had maximum number of genotypes (9) followed by cluster II (8), cluster III (4), cluster V (2), while as clusters IV, VI, VII, VIII were having only one genotype in each cluster. Maximum inter-cluster distances was observed in cluster IV and cluster VI (7021.27), cluster II and VI (5628.93) whereas the maximum intracluster distance was observed in cluster III (770.46) and cluster I (721.11). Highest contribution to divergence observed in lycopene content $(\mathrm{mg} / 100 \mathrm{~g})$, fruit yield $(\mathrm{q} / \mathrm{ha})$ and ascorbic acid content $(\mathrm{mg} / 100 \mathrm{~g})$ and days to red ripen fruit stage. The crosses between the genotypes of cluster VI with IV and Cluster VI with II are likely to exhibit high heterosis and could produce recombinants with desired traits in segregating generations.
\end{abstract}

\section{A B S T R A C T}

A field experiment was laid out in a Randomized Complete Block Design with 27 genotypes of tomato in three replications. The present investigation is to find out

\section{Introduction}

Tomato (Solanum lycopersicum L.) is an important member of Solanaceae family having chromosome number of $2 n=2 x=24$. The probable ancestor of tomato is Solanum lycopersicum var. cerasiforme Bailey. It is originated in wild form in the Peru Equador region of Andes (South America) and it is grown in almost every corner of the world
(Robertson and Labate, 2007). It is typically day neutral plant and is mainly selfpollinated, but a certain percentage of cross pollination also occurs (Depra et al., 2014). Tomato is universally treated as "Protective food" (Thamburaj and Singh, 2013). It is a very good source of income to small and marginal farmers and has a great nutritional value. Tomato is a rich source of minerals, vitamins and organic acids. It is a reservoir of 
diverse antioxidant like ascorbic acid, vitamin C, carotenoides, flavonoides and phenolic acids. Ascorbic acid content in tomato is 31 $\mathrm{mg} / 100 \mathrm{~g}$. Red colour of tomato is due to the presence of pigment 'lycopene' and it is 20$50 \mathrm{mg} / 100 \mathrm{~g}$ in edible portion. Tomato is the world's largest vegetable crop after potato and sweet potato. The major tomato producing states in the country are Madhya Pradesh, Odisha, Andhra Pradesh, Karnataka, Gujarat, West Bengal, Maharashtra, Uttar Pradesh, Chattisgarh, Haryana, Tamil Nadu and Telangana. These states contribute about $91 \%$ of the total production of the country. Tomato is having the an area of about 0.81 million hactares and with a production of 20.51 Million metric tonnes respectively (Horticulture Statistics Division, Department of Agriculture, 2018-19).

Information on the extent of genetic diversity among genotypes is very important in crosses between groups with maximum genetic divergence that would be more responsive for improvement since they are likely to produce desirable recombination and segregation in their progenies after hybridization (Norden, 1980; Reddy, 1988). To have this type of knowledge, research on genetic diversity is very essential. So far a number of research activities have been conducted by different research institutions and researchers in Ethiopia. Since 1969, about 300 tomato lines/cultivars of both short and tall set openpollinated genotypes and hybrids have been introduced by Melkassa Agricultural Research Centre (MARC) from international seed companies, and from Asian Vegetable Research and Development Center (AVRDC). The lines have been tested at different research centers to identify lines having high fruit yield and good quality, resistance/ tolerance to diseases as well as insect pests (Lemma, 2002). It is because of the efforts a number of varieties released for different agro ecologies. Regarding diversity studies a number of authors' from different countries viz., Sekhar et al., (2008), Agong (2001), Naz et al., (2013) and Cebolla-Cornejo et al., (2013) studied genetic diversity in tomato genotypes. However, little information is available with respect to diversity study on tomato genotypes preserved under Ethiopian condition. Therefore, a study was conducted to estimate the genetic diversity among different tomato genotypes.

\section{Materials and Methods}

The present investigation entitled "Genetic divergence studies in Tomato (Solanum lycopersicum L.)" was undertaken at vegetable Experimental Farm of Division of Vegetable Science, SKUAST-Kashmir, Shalimar during summer 2018. The site is situated $34^{\circ} \mathrm{N}$ of latitude and $74.89^{\circ} \mathrm{E}$ of longitude. The climate is temperate characterized by mild summers. June and July are the hottest months while January and February are the coldest. The maximum rainfall is received during March to April. Twenty seven diverse genotypes of tomato were evaluated for various yield and yield attributing traits. The genotypes were grown in a Randomized Complete Block Design (RCBD) with three replications. The details of genotypes along with their source are given in the Table- 1 .

The experimental field consisted of 27 treatments in each replication, such that there were 81 treatments (genotypes) in total. The spacing followed for the row to row and plant to plant distance is $60 \times 35 \mathrm{~cm}$. The experimental field was well prepared and standard cultural, manural and plant protection practices were followed to ensure a healthy crop. Observations recorded on twenty two characters i.e., plant height $(\mathrm{cm})$, plant spread $(\mathrm{cm})$, number of primary branches plant ${ }^{-1}$, days to first flowering, days to $50 \%$ flowering, days to fruit set, days to red ripen fruit stage, fruit length $(\mathrm{cm})$, fruit diameter $(\mathrm{cm})$, average fruit weight $(\mathrm{g})$, 
number of locules fruit ${ }^{-1}$, pericarp thickness $(\mathrm{cm}), 1000$ seed weight $(\mathrm{g})$, seed weight fruit ${ }^{-1}$ $(\mathrm{mg})$, number of fruits plant ${ }^{-1}$, fruit yield plot $^{-1}$ $(\mathrm{kg})$, fruit yield $(\mathrm{q} / \mathrm{ha})$, total soluble solids $(\%)$ ascorbic acid $(\mathrm{mg} / 100 \mathrm{~g})$, lycopene content $(\mathrm{mg} / 100 \mathrm{~g})$, titrable acidity $(\%)$, juice to pulp ratio were studied for various statistical and biometrical parameters. Mahalanobis (1936) generalized distance $\left(D^{2}\right)$ was used to determine the degree of divergence and the genotype were grouped into clusters following Tocher's method (Rao, 1952).

\section{Results and Discussion}

\section{Genetic Divergence}

Mahalanobis $\mathrm{D}^{2}$ statistics helped in grouping of different genotypes of tomato into clusters. In the present investigation, 27 genotypes were grouped into eight clusters based on their $\mathrm{D}^{2}$ values, presented in table-2 Cluster I (9) (Kashi Hemanth, TOLCV-16, Jawahar-99, Kashi Chayan, 2016/TODVAR-5, 2016/TODVAR-11, TOLCV-32, Kashi Amrit, Kashi Anupam) had highest number of genotypes followed by cluster II (8) (2015/TODHYB-1, 2016/TODVAR-2, Marglobe, 2015/TODHYB-4, Kashi Aman, Roma, VRT-13, Kashi Vishesh), III (4) (TOLCV-28, 2016/TODVAR-10, Sel.7, Shalimar Hybrid Tomato-1), V (2) (2016/TODVAR-3, 2016/TODVAR-1) and the clusters IV (1) (2016/TODVAR-12), VI (1) (Kashi Sharad), VII (1) (VRT-19) and VIII (1) (VRT-01) were having only one genotype in each respectively.

Similar studied based on $\mathrm{D}^{2}$ statistic were also performed by Arun Kumar et al., (2016), Nalla et al., (2014) and Lekshmi and Celine (2016).

\section{Average intra and inter cluster distances}

The estimates of intra and inter-cluster distances represented by $\mathrm{D}^{2}$ values are given in Table-3. Minimum intra-cluster distance was found for 0.00 (cluster IV) followed by cluster VI, VII, VIII and maximum was recorded for 770.46 (cluster III). The maximum inter cluster distance was observed between cluster IV and cluster VI (7021.27), which suggested that members of these two clusters are genetically very diverse to each other. The inter cluster distance between cluster II to VI (5628.23), cluster I to cluster VI (3942.27), cluster V to cluster VI (3867.83), cluster IV to cluster VIII (3674.16), cluster VI to cluster VIII (3545.38), cluster VI to VIII (3110.53), cluster VI to cluster VII (2653.04), cluster II to cluster IV (2570.88), cluster II to cluster III (2500.68) and cluster I to cluster VIII (2219.51) were very high. The minimum inter cluster $\mathrm{D}^{2}$ values were recorded in case of cluster I to cluster V (1326.42). The higher inter-cluster distance indicated greater genetic divergence between the genotypes of those clusters, while lower inter-cluster values between the clusters suggested that the genotypes of the clusters were not much genetically diverse from each other. These results of genetic diversity study were in agreement with that of Mahesh et al., (2006), Prashanth et al., (2007), Reddy et al., (2013), Nalla et al., (2014), Lekshmi and Celine (2016), Arun Kumar et al., (2016).

\section{Per cent contribution of the traits}

The contribution percentages of traits under studied towards total divergence are tabulated in Table 4. The highest contribution in the manifestation of genetic divergence was exhibited by lycopene content (31.34\%) followed by fruit yield (q/ha) (27.92\%), ascorbic acid content (26.5\%), days to red ripen fruit stage $(6.84 \%)$, juice to pulp ratio $(2.58 \%)$, days to $50 \%$ flowering $(1.99 \%)$, whereas, days to fruit set $(0.85 \%)$, plant height, fruit length, total soluble solids $(0.57 \%)$, days to first flowering, pericarp 
thickness $(0.28 \%)$ had minimum contribution $(0.36 \%)$ towards total divergence. The contribution of remaining trait in manifestation of genetic divergence was zero. These result are in similar with the findings of Lekshmi and Celine (2016) in tomato.

Table.1 List of genotypes of Tomato (Solanum lycopersicum L.)

\begin{tabular}{|c|c|c|}
\hline S.No. & Genotype/ Variety & Source \\
\hline 1. & Kashi Hemanth & IIVR (Varanasi) \\
\hline 2. & Kashi Amrit & IIVR (Varanasi) \\
\hline 3. & Kashi Sharad & IIVR (Varanasi) \\
\hline 4. & Kashi Vishesh & IIVR (Varanasi) \\
\hline 5. & Kashi Chayan & IIVR (Varanasi) \\
\hline 6. & Kashi Aman & IIVR (Varanasi) \\
\hline 7. & Kashi Anupam & IIVR (Varanasi) \\
\hline 8. & TOLCV- 16 & IIVR (Varanasi) \\
\hline 9. & TOLCV- 28 & IIVR (Varanasi) \\
\hline 10. & TOLCV- 32 & IIVR (Varanasi) \\
\hline 11. & VRT- 01 & IIVR (Varanasi) \\
\hline 12. & VRT- 19 & IIVR (Varanasi) \\
\hline 13. & VRT- 13 & IIVR (Varanasi) \\
\hline 14. & Sel- 7 & IIVR (Varanasi) \\
\hline 15. & Jawahar- 99 & IIVR (Varanasi) \\
\hline 16. & 2016/TOVDVAR- 12 & AICRP, IIVR ( Varanasi) \\
\hline 17. & 2016/TODVAR- 11 & AICRP, IIVR (Varanasi) \\
\hline 18. & 2016/TODVAR- 1 & AICRP, IIVR (Varanasi) \\
\hline 19. & 2016/TODVAR- 3 & AICRP, IIVR (Varanasi) \\
\hline 20. & 2016/TODVAR- 10 & AICRP, IIVR (Varanasi) \\
\hline 21. & 2016/TODVAR- 5 & AICRP, IIVR (Varanasi) \\
\hline 22. & 2016/TODVAR- 2 & AICRP, IIVR (Varanasi) \\
\hline 23. & 2015/TODHYB- 4 & AICRP, IIVR (Varanasi) \\
\hline 24. & 2015/TODBYB- 1 & AICRP, IIVR (Varanasi) \\
\hline 25. & Roma & SKUAST-K, Shalimar \\
\hline 26. & Shalimar Hybrid Tomato-1 & SKUAST-K, Shalimar \\
\hline 27. & Marglobe & SKUAST-K, Shalimar \\
\hline
\end{tabular}


Table.2 Distribution of tomato genotypes in different clusters

\begin{tabular}{|c|c|c|}
\hline $\begin{array}{c}\text { Cluster } \\
\text { Number }\end{array}$ & $\begin{array}{c}\text { Number of } \\
\text { genotypes } \\
\text { included }\end{array}$ & Name of genotypes \\
\hline I & 9 & $\begin{array}{c}\text { Kashi Hemanth, TOLCV-16, Jawahar-99, Kashi Chayan, } \\
\text { 2016/TODVAR-5, 2016/TODVAR-11, TOLCV-32, } \\
\text { Kashi Amrit, Kashi Anupam }\end{array}$ \\
\hline II & 8 & $\begin{array}{c}\text { 2015/TODHYB-1, 2016/TODVAR-2, Marglobe, } \\
\text { 2015/TODHYB-4, Kashi Aman, Roma, VRT-13, Kashi } \\
\text { Vishesh }\end{array}$ \\
\hline III & 4 & TOLCV-28, 2016/TODVAR-10, Sel.7, Shalimar Hybrid \\
& & Tomato-1 \\
\hline IV & 1 & 2016/TODVAR-12 \\
\hline V & 2 & 2016/TODVAR-3, 2016/TODVAR-1 \\
\hline VI & 1 & Kashi Sharad \\
\hline VII & 1 & VRT-19 \\
\hline VIII & 1 & VRT-01 \\
\hline
\end{tabular}

Table.3 Average intra cluster (Diagonal) and inter cluster (Above Diagonal) distance values in tomato (Solanum lycopersicum L.)

\begin{tabular}{|l|c|c|c|c|c|c|c|c|c|}
\hline $\begin{array}{c}\text { S. } \\
\text { No. }\end{array}$ & Cluster & I & II & III & IV & V & VI & VII & VIII \\
\hline $\mathbf{1 .}$ & I & $\mathbf{7 2 1 . 1 1}$ & 1553.66 & 1767.13 & 1352.41 & 1326.42 & 3942.47 & 1328.15 & 2219.51 \\
\hline $\mathbf{2 .}$ & II & & $\mathbf{6 7 0 . 5 7}$ & 2500.68 & 2367.26 & 2570.88 & 5628.93 & 1774.97 & 1287.58 \\
\hline $\mathbf{3 .}$ & III & & & $\mathbf{7 7 0 . 4 6}$ & 3590.15 & 1995.72 & 1378.56 & 1601.37 & 1384.33 \\
\hline $\mathbf{4 .}$ & IV & & & & $\mathbf{0 . 0 0}$ & 1270.36 & 7021.27 & 3560.14 & 3674.16 \\
\hline $\mathbf{5 .}$ & V & & & & & $\mathbf{5 2 9 . 6 3}$ & 3867.83 & 2514.61 & 3110.53 \\
\hline $\mathbf{6 .}$ & VI & & & & & & $\mathbf{0 . 0 0}$ & 2653.04 & 3545.38 \\
\hline $\mathbf{7 .}$ & VI & & & & & & & & \\
\hline $\mathbf{8 .}$ & VIII & & & & & & & & \\
\hline
\end{tabular}


Table.4 Percent contribution in twenty two characters towards total divergence in tomato

\begin{tabular}{|c|c|c|}
\hline Source & Contribution \% & Times ranked $1^{\text {st }}$ \\
\hline Plant height (cm) & 0.57 & 2.000 \\
\hline Plant spread (cm) & 0.00 & 0.000 \\
\hline $\begin{array}{c}\text { Number of primary branches } \\
\text { plant }^{-1}\end{array}$ & 0.00 & 0.000 \\
\hline Days to first flowering & 0.28 & 1.000 \\
\hline Days to fruit set & 0.85 & 3.000 \\
\hline Days to $50 \%$ flowering & 1.99 & 7.000 \\
\hline Days to red ripen fruit stage & 6.84 & 24.000 \\
\hline Fruit length $(\mathrm{cm})$ & 0.57 & 2.000 \\
\hline Fruit diameter (cm) & 0.00 & 0.000 \\
\hline Average fruit weight (g) & 0.00 & 0.000 \\
\hline Number of locules fruit ${ }^{-1}$ & 0.00 & 0.000 \\
\hline Pericarp thickness (cm) & 0.28 & 1.000 \\
\hline 1000 Seed weight (g) & 0.00 & 0.000 \\
\hline Seed weight fruit ${ }^{-1}(\mathrm{mg})$ & 0.00 & 0.000 \\
\hline Number of fruits plant ${ }^{-1}$ & 0.00 & 0.000 \\
\hline Fruit yield plot ${ }^{-1}(\mathrm{~kg})$ & 0.00 & 0.000 \\
\hline Fruit yield (q/ha) & 27.92 & 98.000 \\
\hline Total soluble solids (\%) & 0.57 & 2.000 \\
\hline Lycopene content (mg/100g) & 31.34 & 110.000 \\
\hline $\begin{array}{l}\text { Ascorbic acid content } \\
(\mathrm{mg} / \mathbf{1 0 0 g})\end{array}$ & 26.5 & 93.000 \\
\hline Titrable acidity (\%) & 0.00 & 0.000 \\
\hline Juice to pulp ratio & 2.28 & 8.000 \\
\hline
\end{tabular}

The 27 genotypes of tomato germplasm were grouped into 8 clusters. The crosses between members of clusters separated by high inter cluster distance are likely to produces desirable segregates. The very high inter cluster value was observed between the cluster IV and cluster VI, which suggested that members of these two clusters are genetically very diverse to each other. The inter cluster distance between cluster II to VI, cluster I to cluster VI, cluster V to cluster VI, cluster IV to cluster VIII.

Therefore the breeder choose the genotypes of clusters as parents which are showing high inter-cluster distance between them to produce recombinants and desirable segregates in crop improvement programme. Maximum percent contribution was observed for lycopene content followed by fruit yield (q/ha), ascorbic acid content, titrable acidity, days to red ripen fruit stage, juice to pulp ratio, days to $50 \%$ flowering.

\section{Acknowledgements}

I am highly thankful to Division of vegetable science, Division of Plant Breeding and Genetics, Sher-e-Kashmir University of Agricultural Sciences \& Technology, Shalimar, Srinagar for providing the facilities for conducting the research. 


\section{References}

Agong SG (2001). Genetic variation of Kenyan tomato (Lycopersicon esculentum L.) germ plasm. J. Food Technol. Afr. 6(1): 13-17. http://dx.doi.org/10.4314/jfta.v6i1.1927 7.

Arun-Kumar, P., Ravindar-Reddy, K., Reddy, R. V. S. K., Pandravada, S. R. and Saidaiah, P. 2016. Genetic divergence studies in tomato genotypes, Supplement on Genetics and Plant Breeding 11(4): 3071-3074.

Cebolla-Cornejo J, Roselló S, Nuez F (2013). Phenotypic and genetic diversity of Spanish tomato landraces. Scientia Horticulturae 162: 150-164.

Depra, M. S., Delaqua, G. C., Freitas, L. and Cristina, M. 2014. Pollination deficit in open field tomato crops (Solanum lycopersicum L.) in Riode Janeiro State, Southeast Brazil. Journal of Pollination Ecology 12(1): 1-8.

Lekshmi, S. L. and Celine, V. A. 2016. Genetic diversity studies in tomato (Solanum lycopersicum L.) under protected conditions. International Journal Current Microbiological Applied Science 5(4): 212-215.

Lemma D (2002). Tomatoes Research Experience and Production Prospects. Research Report No. 43. Ethiopian Agricultural Research Organization, Addis Ababa. pp. 1-15.

Mahalanobis, P. C. 1936. A statistical study at Chinese head measurement. Journal of Statistics Society Bengal 25: 301-377.

Mahesh, D. K., Apte, Y. B. and Jadhav, B. B., 2006. Studies on genetic divergence in tomato (Lycopersicon esculentum Mill.). Crop Research 32(2): 401-402.

Nalla, M. K., Rana, M. K., Singh, S. J., Sinha, A. K., Reddy, P. K. and Mohapatra, P. P. 2014. Assessment of genetic diversity through $\mathrm{D}^{2}$ analysis in tomato (Solanum lycopersicum L.). International Journal of Innovation and Applied Studies 6(3): 431-438.

Naz S, Zafrullah A, Shahzadhi K, Munir N (2013). Assessment of genetic diversity within germplasm accessions in tomato using morphological and molecular markers. J. Anim. Plant Sci. 23: 1099- 1106.

Norden AJ (1980). Breeding methodology in groundnut. Proceedings of the International Workshop on Groundnut, 13-17 October 1980, Patancheru, India, International Crop Research Institute for the Semi Arid Tropics, pp. 58-61.

Rajasekhar, B. R., Reddy, M. R., Begum, H. and Sunil, N. 2013. Genetic diversity studies in tomato (Solanum lycopericum L.) IOSR-Journal of agriculture and Veterinary Sciences 4: 2319-2380.

Rao, C. R. 1952. Advanced statistical methods in biometrical research. Ed. J. John Wiley and Sons, Inc. New York pp. 198-201.

Robertson, L. D. and Labate J. A. 2007. Genetic resources of tomato (Lycopersicum esculentum var. esculentum) and Wild Relatives. Genetic Improvement of Solanaceus Crops 2: 25-75.

Reddy PS (1988). Genetics, Breeding and Varieties. In: Reddy PS (ed). Groundnut Publication and Information Division. Indian Council of Agricultural Research, New Delhi, pp. 200- 217.

Sekhar L, Prakash BG, Salimoth PM, Sridevi O, Gatil AA (2008). Genetic diversity among some productive

hybrids of tomato (Lycopersicon esculentum Mill). Karanataka J. Agric.

Sci. 21(2): 264- 265.

Thamburaj, S. and Singh, N. 2013. Tomato. In: Vegetables, tuber crops and spices. ICAR publishers, New Delhi pp. 10-28. 
How to cite this article:

Srinivasulu. B, Pradeep Kumar Singh, G. Harika and Sai Prashanth. C. 2020. Genetic Diversity among Tomato (Solanum Lycopersicum L.) Genotypes. Int.J.Curr.Microbiol.App.Sci. 9(02): 2906-2913. doi: https://doi.org/10.20546/ijcmas.2020.902.330 